\title{
Stress Corrosion Cracking of a X60 Steel in Carbonated Media.
}

\author{
Avilez A., Flores O., Aguilar A., Martínez H.
}

\begin{abstract}
Cracking in steel pipes caused by the corrosion suffered by the material due to the transport of hydrocarbons generates significant economic losses, and even human losses, as well as damage to the environment, so it is very important to know and determine the origin and mechanism whereby a medium rich in $\mathrm{H}_{2} \mathrm{CO}_{3}$ induces cracking in API X60 steel ducts that are used in the transportation of hydrocarbons in Mexico. Stress corrosion cracking testing of $\mathrm{X60}$ steel in an alkaline solution $(\mathrm{pH}=9)$ of sodium bicarbonate $\left(\mathrm{NaHCO}_{3}\right)$ at room temperature, at a concentration of $0.1 \mathrm{M}$ was performed. A MWOL (Modified Wedge Open Loading) specimen was used to measure the susceptibility to cracking and propagation of steel. It was found that the $\mathrm{X60}$ steel after having fulfilled the test time established in the TM-0177 standard and once it was evaluated microscopically, did not show to be susceptible to the SCC phenomenon in a medium of sodium bicarbonate in the different experimental conditions.
\end{abstract}

Index term-Cracking, Hydrocarbons, Losses, Stress Corrosion Cracking, Susceptibility.

\section{INTRODUCTION}

During the production of oil and gas, its transmission, refining, and subsequent use as fuel and as raw material in the chemical industry, constitute very complex processes. In these processes there are several problems, with corrosion being one of the most important [1]. The number of pipelines that are in use in our country an average of 54 thousand kilometers, with more than two kilometers located in submarine zones where crude oil, natural gas, bitter gas, sweet gas, gasoline, diesel, and other vehicles are used to transport refined products to places where it is required for local consumption [2]. Nearly half of the conduits have more than 40 years of operation. Despite the constant maintenance, material failures are caused by corrosion. One of the main means for the transfer of hydrocarbons, which are of great importance and also make all efforts aimed at preventing deterioration, offers both technological and economic advantages [3], [4], [5]. The costs for loss of time, repair, and change of deteriorated materials in ducts and extraction equipment are very high. If the deterioration is not adequately controlled, it can become the cause of various accidents and catastrophic damage to the environment. Corrosion causes

Avilez O. Angel, Universidad Autonoma del Estado de Morelos/ Facultad de Ciencias Químicas e Ingenierías, Cuernavaca, Morelos.

Flores C. Osvaldo, Universidad Nacional Autonoma de México/ Instituto de Ciencias Físicas, Cuernavaca, Morelos.

Aguilar N. Andrés, Universidad Autonoma del Estado de Morreos/ Facultad de Ciencias Químicas e Ingenierías., Cuernavaca, Morelos.

Martínez V. Horacio, Universidad Nacional Autonoma de México/ Instituto de Ciencias Físicas, Cuernavaca, Morelos. millions and even human losses by: explosions, which cause deaths; contamination, derived from oil spills; or damage to metal parts, oil pipelines, oil rigs, water pipes, bridges, domestic heaters, and car exhaust pipes. [8]. One of the most frequent types of physical damages in these pipelines is the failure due to cracking. The knowledge and determination of the origin and mechanism of this failure is of great interest, since it imposes a challenge to various disciplines such as electrochemistry applied to corrosion, metallurgy, and fracture mechanics, to generate and expand the knowledge of this phenomenon. This contributes to increase the integrity of existing pipelines. Guidelines are needed to avoid recurrence, as well as evaluating materials and alternative alloys for the construction of new distribution and transport pipelines, with better resistance to corrosion and superior mechanical properties. It is known in the oil industry [5], [6] that cracking not only in pipelines, but also in well drilling machines and equipment such as storage tanks and valves, among others. It is induced by various corrosive media that may contain aggressive chemical species, as well as microorganisms and salts [2]. These means are found in the fluids that are transported in the pipelines of the National Petroleum Industry. In these media there are significant amounts of $\mathrm{CO} 2$, $\mathrm{H} 2 \mathrm{~S}$, and bitter condensates [6], [7]. It is of interest for this research to determine the causes by which a medium rich in $\mathrm{H} 2 \mathrm{CO} 3$ induces cracking in API X60 steel ducts, ducts that are used in the transportation of hydrocarbons in Mexico.

\section{EXPERIMENTAL PROCEDURE}

The test material was obtained from a gas transmission pipe (457.2 mm diameter, $6 \mathrm{~mm}$ wall thickness). The material was a simple carbon steel API X-60, whose composition is shown in table 1.

Table 1. Chemical composition of X60 Steel

\begin{tabular}{|c|c|c|c|c|c|c|c}
\hline \multirow{4}{*}{ X60 } & $\mathrm{C}$ & $\mathrm{Mn}$ & $\mathrm{Si}$ & $\mathrm{S}$ & $\mathrm{P}$ & $\mathrm{Ni}$ & $\mathrm{Cr}$ \\
\cline { 2 - 8 } & 0.0227 & 1.472 & 0.1286 & 0.0024 & 0.0155 & 0.1597 & 0.2508 \\
\cline { 2 - 8 } & $\mathrm{Mo}$ & $\mathrm{Cu}$ & $\mathrm{Nb}$ & $\mathrm{V}$ & $\mathrm{Ti}$ & $\mathrm{B}$ & $\mathrm{Al}$ \\
\cline { 2 - 8 } & 0.0144 & 0.3111 & 0.1045 & - & \multicolumn{2}{|c|}{0.1205} & 0.0518 \\
\hline
\end{tabular}

Stress tests threw out that the elastic limit varied between 370.7 MPa and 484.5 MPa [9]. Modified tension compact fracture mechanics specimens were designed by Novak and Rolfe (Fig. 1) [10], known as M-WOL in accordance with ASTM E 399-97 [11]. To determine the behavior of the steel in the proposed medium. After the machining, a coarse polishing of the notch was carried out using abrasive sandpaper from 80 to 2000 grain, in order to observe the growth of the crack. 


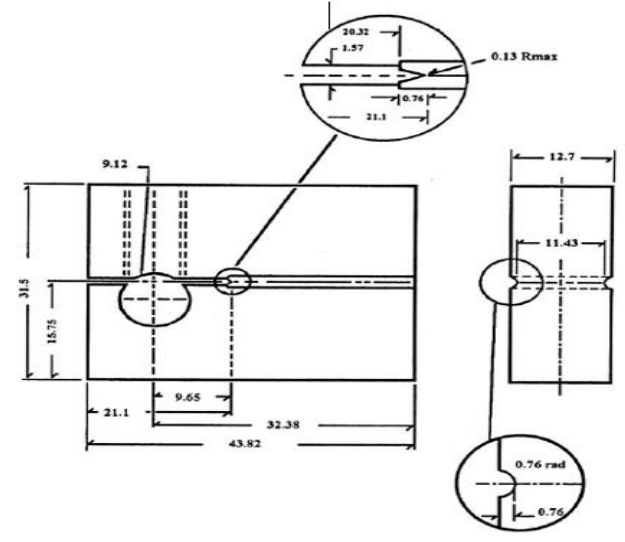

Fig. 1. Dimensions of the WOL Specimen Test in mm.

To perform the study of cracking and crack propagation velocities in steels and their interaction with the microstructure, the M-WOL specimens are pre-cracked and subsequently loaded at $95,80,65$, and $50 \%$ of the yield limit of the steels, applying the technique of deformation of the opposite face [12].

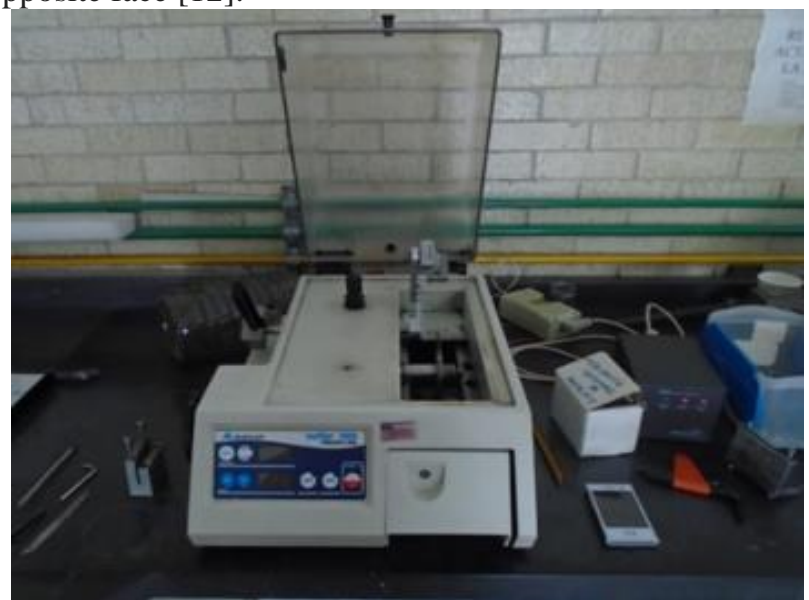

Fig. 2. Pre-cracked with Diamond Disk

A precision saw and a diamond-tipped disk with a thickness of 0.014 in were used to have an area almost free of deformation due to the machining cut and as clean as possible (Fig. 2). Once this process was carried out, the strain gages were placed in order to make the static loading (Fig. 3).

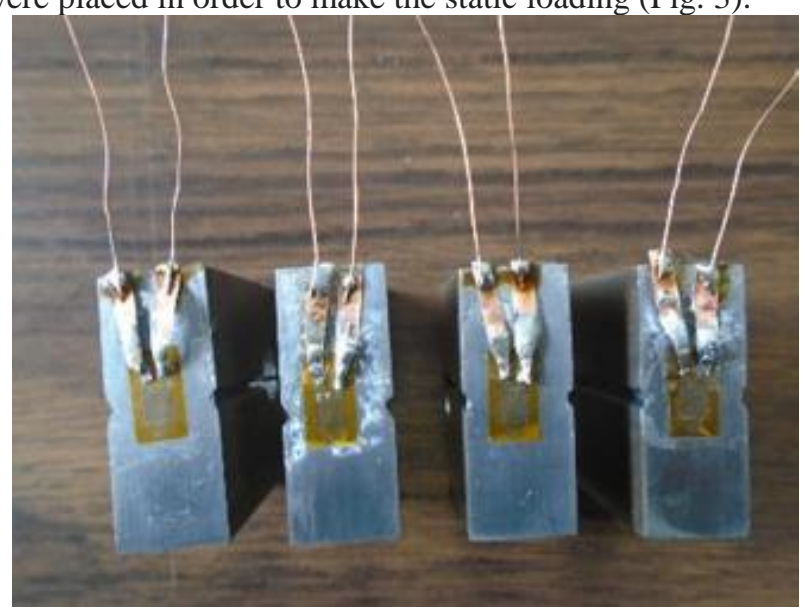

Fig. 3. Glue of Extensiometric Gauges.

The formulas established in the ASTM E399-90 standard and the manual Stress Corrosion Cracking Test Methods were used [11], [13].

$$
\mathrm{k}_{\mathrm{I}}=\frac{\sigma_{\mathrm{ys}}}{\mathrm{B} \sqrt{\mathrm{w}}} \mathrm{f}\left(\frac{\mathrm{a}}{\mathrm{w}}\right)
$$

Where:

$\mathrm{K}_{\mathrm{I}}$ : Initial Effort

$\sigma_{\mathrm{YS}}:$ Yield Strength

B : Thickness

a : Crack initial length

w : Specimen Width

$$
\mathrm{K}_{\mathrm{IC}}=\frac{\mathrm{P}_{\mathrm{Q}}}{\mathrm{B} \sqrt{\mathrm{W}}} \mathrm{f}\left(\frac{\mathrm{a}}{\mathrm{w}}\right)
$$

Where:

$\mathrm{K}_{\mathrm{IC}}$ : Fracture Toughness

$\mathrm{P}_{\mathrm{Q}}:$ Applied Load

$$
\begin{gathered}
f\left(\frac{\mathrm{a}}{\mathrm{w}}\right)=\frac{\left(2+\frac{\mathrm{a}}{\mathrm{w}}\right)\left[0.886+4.64 \frac{\mathrm{a}}{\mathrm{w}}-13.32\left(\frac{\mathrm{a}}{\mathrm{w}}\right)^{2}+14.72\left(\frac{\mathrm{a}}{\mathrm{w}}\right)^{3}-5.6\left(\frac{\mathrm{a}}{\mathrm{w}}\right)^{4}\right]}{\left(1-\frac{\mathrm{a}}{\mathrm{w}}\right)^{\frac{3}{2}}} \\
\mathrm{~K}_{\text {ISCC }}=V E\left(\sqrt{\frac{\mathrm{B}}{\mathrm{a}_{\text {arrest }}-\mathrm{B}_{\mathrm{n}}}}\right) \times\left(\frac{\mathrm{c}_{3}}{\mathrm{c}_{6}}\right)
\end{gathered}
$$

Where:

$\mathrm{K}_{\mathrm{ISCC}}$ : Threshold Effort

$\mathrm{V}:$ Crack opening

E : Young's modulus

$\mathrm{B}_{\mathrm{n}}: 5 \%$ Specimen thickness

$\mathrm{c}_{3} \mathrm{Yc}_{6}:$ Constants

$$
\begin{gathered}
c_{3}=30.96\left(\frac{a}{w}\right)-195.8\left(\frac{a}{w}\right)^{2}+730.6\left(\frac{a}{w}\right)^{3}-1186.3\left(\frac{a}{w}\right)^{4}+754.6\left(\frac{a}{w}\right)^{5} \\
c_{6}=\exp \left(3.453-8.097\left(\frac{a}{w}\right)+42.314\left(\frac{a}{w}\right)^{2}-64.677\left(\frac{a}{w}\right)^{3}+36.845\left(\frac{a}{w}\right)^{4}\right)
\end{gathered}
$$

A solution of distilled water with sodium bicarbonate $\left(\mathrm{NaHCO}_{3}\right)$ was used in a composition of $0.1 \mathrm{M}(8.4 \mathrm{~g} / 1)$ with a $\mathrm{pH}=9$ and at room temperature. The samples were evaluated by optical microscopy and $\mathrm{pH}$ measurement to determine the crack growth and test time, following the NACE TM-0177 standard that establishes 720 hours as the maximum time to determine the susceptibility to crack growth [14].

The samples, once evaluated, were prepared metalographically by roughing, mirror polishing, and chemical attack, and characterized by optical microscopy.

\section{RESULTS AND DISCUSICON.}

The microstructure observed in X60 steel corresponds mainly to ferrite (clear phase and gray tones) and a low percentage of perlite (dark phase), agreeing with the low carbon content. The distribution of ferrite grain sizes is heterogeneous, equiaxed fine grains with sizes around $5 \mu \mathrm{m}$ can be observed. Also observed are elongated grains with sizes of the order of $30 \mu \mathrm{m}$ in the longitudinal direction and 
International Journal of Engineering and Technical Research (IJETR)

ISSN: 2321-0869 (O) 2454-4698 (P) Volume-8, Issue-9, September 2018

between 10 and $15 \mu \mathrm{m}$ in width. The percentage of nonmetallic phases is minimal, observing the presence of fine precipitates, probably Ti nitrides. A preferential elongation of the grains in vertical direction is observed, which is evidence of the plastic deformation of the microstructure during the thermomechanical process (Fig. 4).

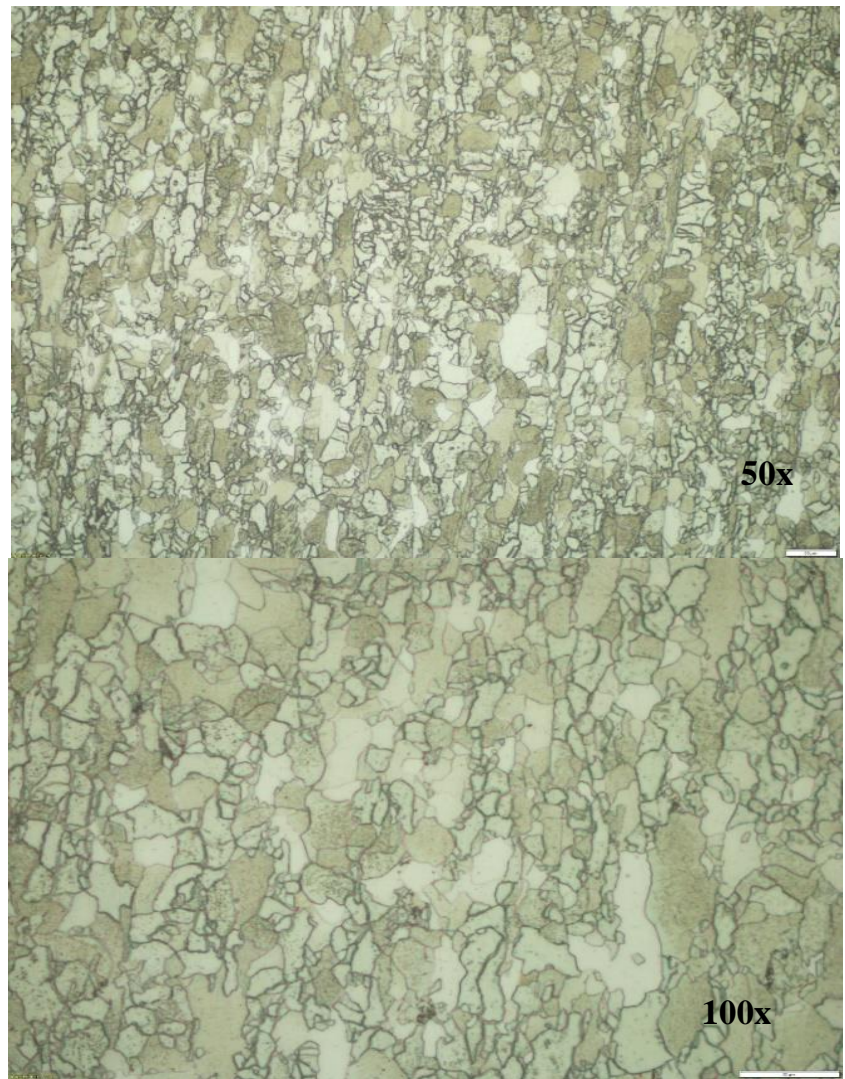

Fig. 4. Microstructure Ferrite Perlite of Steel X60. The dimensions correspond to $20 \mu \mathrm{m}$.

\section{A. Optical microscopy.}

The regions where the cracks grow are shown in Fig. 5. The observed profile corresponds to the cut area with the diamond-edged disk, whose thickness is $0.35 \mathrm{~mm}$. At the amplification shown, no large cracks are observed. But if it is possible to observe the change of the cutting profile associated with the corrosion process in the steel.

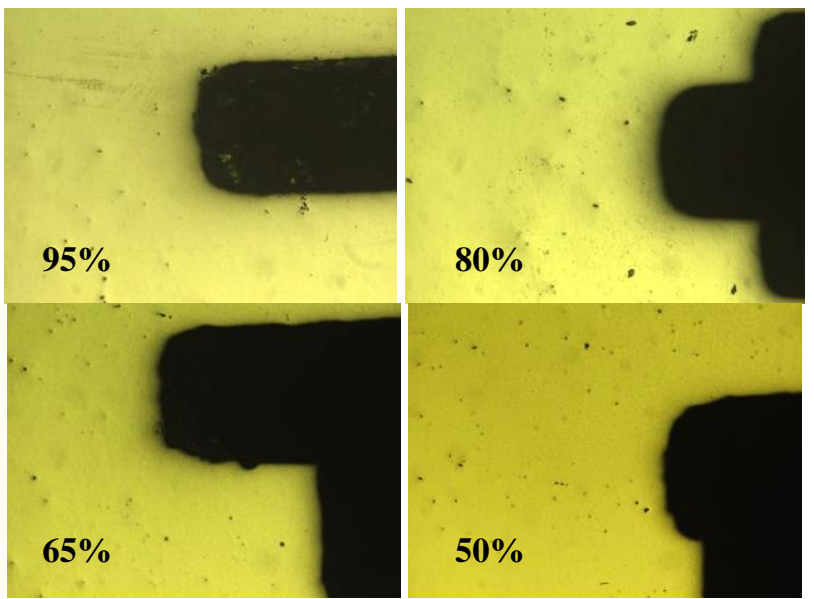

Fig. 5. Steel specimens X60 at different loads.

\section{B. Scanning Electron Microscopy (SEM).}

In Fig. 6. The crack tip generated in specimen 1 is shown. Crack growth is limited despite being the highest applied load. This indicates a great resistance of the X60 steel to the cracking process induced by the corrosion in the environment used in the corrosion tests under stress.

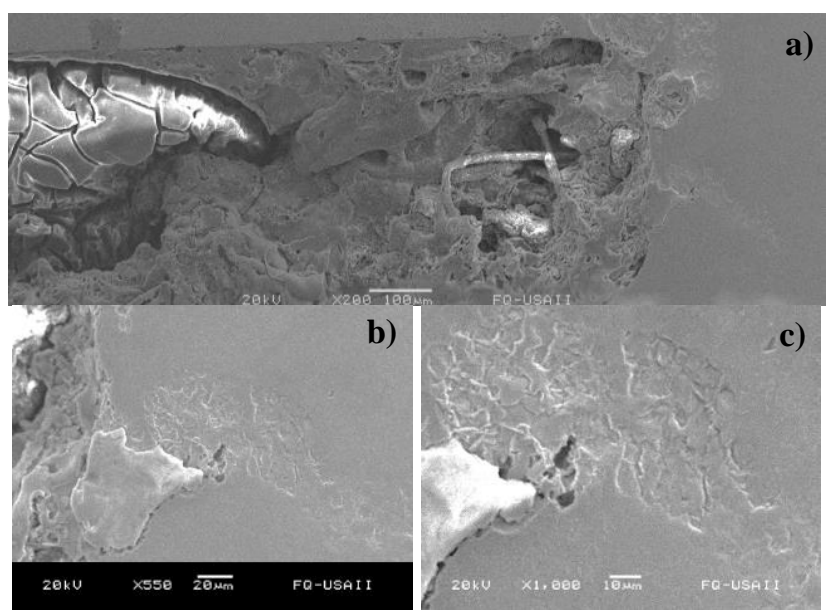

Fig. 6. Specimen $95 \%$ of the Cedence limit.

In Fig. 6a, the region of the diamond edge disk cut is observed. It should be noted that corrosion products are seen inside the cut. In b and c, the region where there is material dissolution and damage to the microstructure is shown at the highest amplification, just at the tip of the crack generated in the steel by the corrosion process under stress.

In Fig. 7. Images corresponding to specimen 2 are shown. Similar to sample 1, at low amplification, material damage is not observed, the edge of the cutting surface is almost unchanged. However, in $b$, there is loss of material on the surface and cracking below the corroded surface.

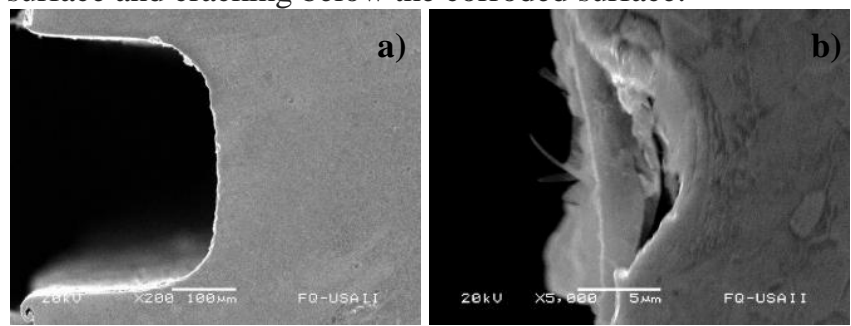

Fig. 7. Specimen $80 \%$ of the cedence limit.

In Fig. 8. Images corresponding to the specimen 3 are shown. In a similar way to the previous ones, corrosion products are observed inside the disk cut with diamond edge. The profile of the cut surface shows dissolution of the material. In $b$, the corroded surface and the corrosion products are observed, as well as the microstructural damage (intergranular corrosion) suffered below the surface.

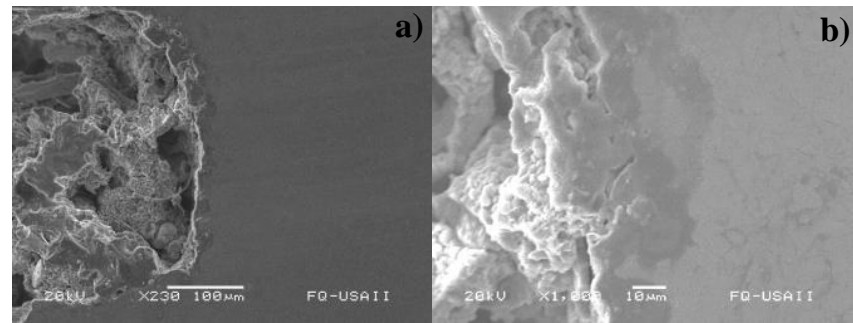

Fig. 8. Specimen $65 \%$ of the cedence limit. 
In Fig. 9. Images corresponding to specimen 4 are shown. Similar to the previous ones, corrosion products are observed inside the disk cut with diamond edge. The profile of the cut surface shows preferential dissolution of the material in the central region of the cut profile with the diamond edge disk. In $\mathrm{b}$, the corroded surface and the corrosion products are observed, as well as the microstructural damage (intergranular corrosion) suffered below the surface.

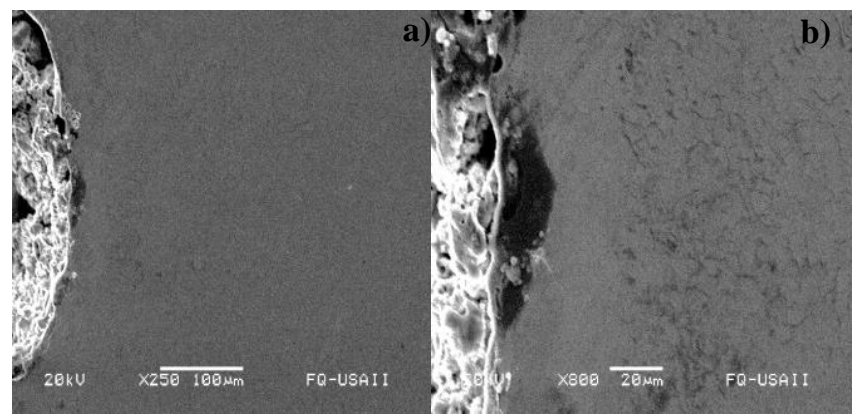

Fig. 9. Specimen $50 \%$ of the cedence limit.

In all four samples, corrosion of the cutting surface and microstructural damage was identified right at the tip of the cracks, identified as intergranular corrosion.

\section{Fracture Surfaces}

The following figures show the fracture surfaces of the samples at different loads which were fractured once they were evaluated in the test solution.

Fig. 10 shows the fracture surface for the sample with the highest intensity of effort at $95 \%$ of the yield limit. It is possible to observe the presence of a fragile surface with tearing systems in the pre-cracking zone.

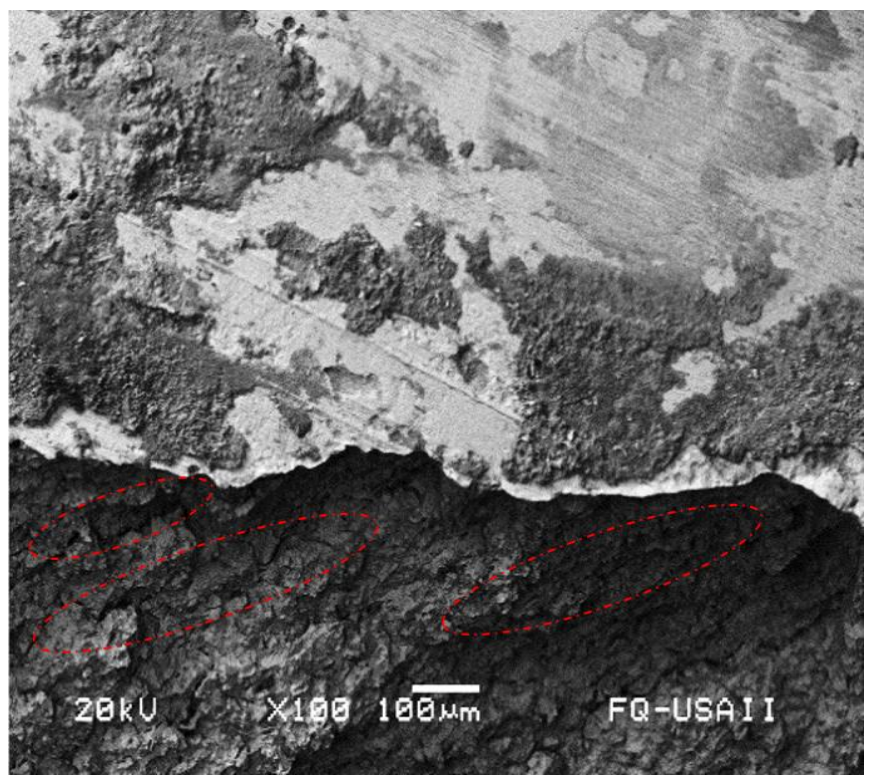

Fig. 10. Fracture Surface, Specimen $95 \%$.

The sample at $80 \%$ yield limit has a ductile-fragile surface, in addition to the presence of small microcavities and cleavage (see Fig. 11).

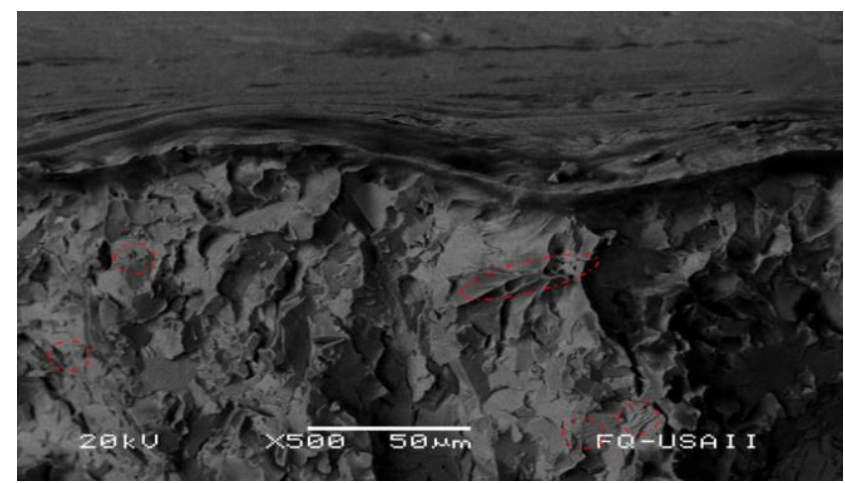

Fig. 11. Fracture Surface, Specimen $80 \%$

Fig. 12 shows the presence of intergranular cracking and the presence of coalescence, denoting a totally fragile surface.

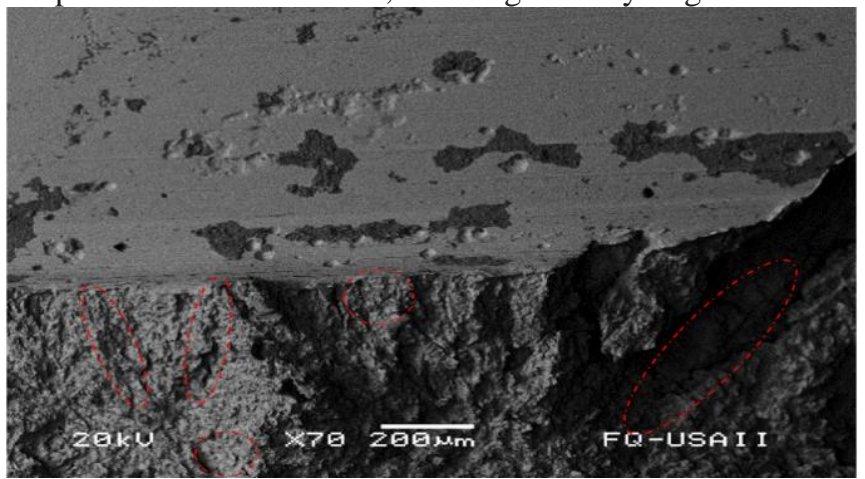

Fig. 12. Fracture Surface, Specimen $65 \%$.

The sample at $50 \%$ of the yield limit presents a totally fragile surface with the presence of tearing systems and the presence of small microcavities in the pre-cracked area (see Fig. 13).

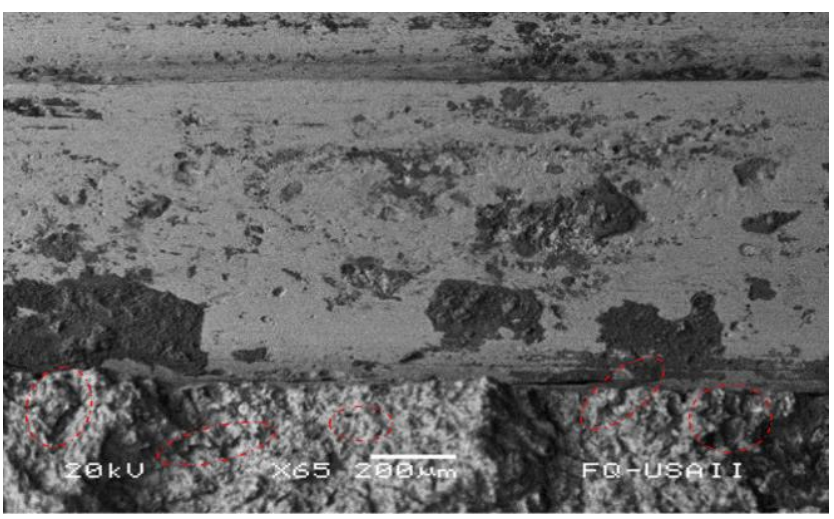

Fig. 13. Fracture Surface, Specimen $50 \%$.

\section{Final Results.}

The results of the stress corrosion tests performed on 4 WOL-M samples of API X60 steel in a sodium bicarbonate solution are shown in the following table.

\begin{tabular}{|c|c|c|c|c|c|c|}
\hline Muestras & $\begin{array}{c}\mathrm{K}_{\mathrm{i}} \\
\mathrm{MPa} \sqrt{\mathrm{m}}\end{array}$ & $\begin{array}{c}\mathrm{K}_{\mathrm{ISCC}} \\
\mathrm{MPa} \sqrt{\mathrm{m}}\end{array}$ & $\frac{\mathrm{a}}{\mathrm{W}}$ & $\begin{array}{c}\mathrm{t}_{\text {inc }} \\
\text { hrs }\end{array}$ & $\begin{array}{c}\mathrm{t}_{\text {tot }} \\
\text { hrs }\end{array}$ & $\begin{array}{c}\text { Longitud } \\
\mathrm{a}_{0}+\mathrm{a}_{\text {arrest }} \\
\mathrm{m}\end{array}$ \\
\hline $\mathbf{1}$ & 1210000,00 & 293,00 & 0,397 & 0 & 720 & 0,0122 \\
\hline $\mathbf{2}$ & 844000,00 & 499,00 & 0,327 & 0 & 720 & 0,0102 \\
\hline $\mathbf{3}$ & 703000,00 & 330,00 & 0,334 & 0 & 720 & 0,0103 \\
\hline $\mathbf{4}$ & 542000,00 & 473,00 & 0,371 & 0 & 720 & 0,0109 \\
\hline
\end{tabular}

Table 2. Final Results of the WOL-M Specimens.

Table 2 shows the samples complied with the established time of 720 hours as established by the NACE Standard 
TM-0177, whereby it can be denoted that the incubation times represent a value without crack growth. Likewise, there is a decrease in its initial values of intensity of effort with respect to the final values of KISCC.

In Figs. 14 and 15, the relation of a/w with respect to time and the intensity factor of effort are shown where a linear trend can be observed demonstrating that there is no crack growth.

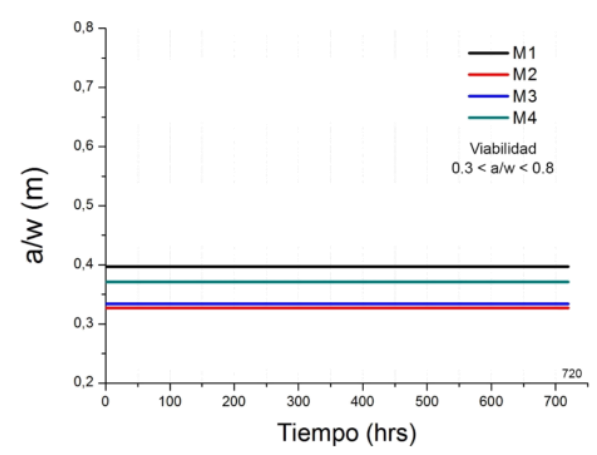

Fig. 14. Crack Growth Graph.

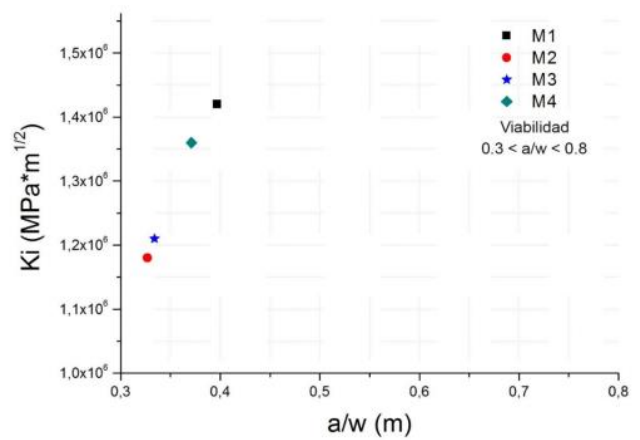

Fig. 15. Graph of relationship between $\mathrm{Ki}$ and a / w.

Fig. 16 shows the relationship of KI vs time, which shows that the material reached $720 \mathrm{hrs}$. Without the presence of crack growth. In general, it is shown that the ratio factor of a / $\mathrm{w}$ is in the range of applicability, as shown in the figures.

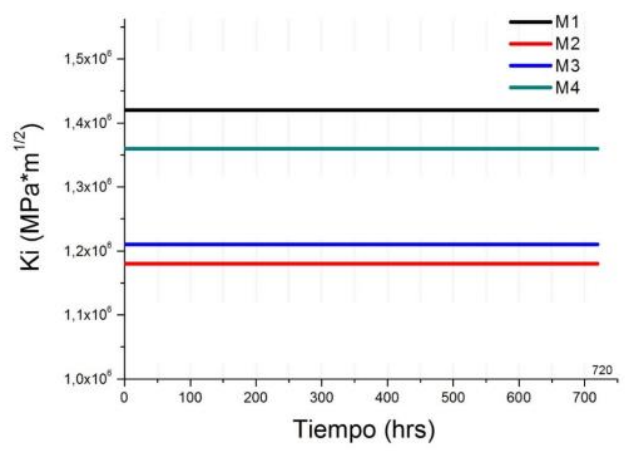

Fig. 16. Graph of Ki vs Time.

\section{CONCLUSIONS}

API X60 steel showed limited crack growth at $720 \mathrm{hrs.} \mathrm{Of}$ test time established by NACE Standard TM-0177. Therefore, it did not appear to be susceptible to the phenomenon of SCC in a medium of sodium carbonate in different experimental conditions.

In general, although there is no accelerated and/or catastrophic growth of the crack, there is damage to the microstructure just in front of the tips of the cracks in the form of intergranular corrosion. It can be concluded that the presence of microcracks and cavities in the sample with the greatest load stress is due to the dissolution mechanism.

The sample with the highest applied load (95\% yield stress) showed the highest susceptibility to crack growth, showing the presence of small micro cracks just opposite the pre-cracked base. The samples with loads of 80,65 and $50 \%$ of the yield stress only showed general corrosion at the base, without the presence of any evidence of growth, but intergranular corrosion was observed just at the base of the pre-cracking.

\section{REFERENCES.}

[1] Fuentes Castañeda Pilar. "Propagación de grietas por corrosión bajo esfuerzo en condiciones de Reactor de Agua Hirviente (BWR)," Instituto Tecnológico de Toluca, Metepec, México. 2003.

[2] American Society for Metals. Metals Handbook. Volume 11. Failure Analysis and Prevention. Ed. Metals Handbook. United States of America. 1986.

[3] González Velázquez Jorge Luis. Metalurgia Mecánica. Ed. Limusa México, D.F. Págs. 143-148. 2003

[4] González Velázquez Jorge Luis. Mecánica de Fractura. Ed. Limusa México, D.F. Pag.37. 2004

[5] Attkinson, J.T.N y Van Droffelar H. Corrosion and its Control. An Introduction to the Subject. NACE. Houston, Texas. USA. 1995.

[6] NACE International. Curso de Corrosión Básica Manual del Estudiante. National Association of Corrosion Engineers. Houston, Texas. 2004

[8]

https://www.nace.org/Newsroom/NACE-News/Study-Sets-Course-To ward-Corrosion-Management-Practices-to-Increase-Safety,-Decrease\$2-5-Trillion-Global-Cost-of-Corrosion/

[9] ASTM E8 / E8M-16a, Standard Test Methods for Tension Testing of Metallic Materials, ASTM International, West Conshohocken, PA, 2016

[10] S.R. Novak and S. T. Rolfe. Modified WOL Specimen for KIscc. Environmental Testing. Journal of Materials Vol 4 No. 3 p. 701-728. 1969.

[11] ASTM E399-09, Standard Test Method for Linear-Elastic Plane-Strain Fracture Toughness K Ic of Metallic Materials, ASTM International, West Conshohocken, PA, 2009.

[12] W.F. Deans and C. E. Richards. A Simple and Sensitive Method of Monitoring Crack and Load in Compact Fracture Mechanics Specimens Using Strain Gages. Journal of Testing and Evaluation, JTVEA, Vol 7 No. 3 p. 147-154. 1979.

[13] A. John Sedriks. Stress Corrosion Cracking Test Methods. Corrosion Testing Made Easy Volume 1. NACE, Houston, Texas. 1990.

[14] NACE International. Standard Test Method. Laboratory Testing of Metals for Resistance to Sulfide Stress Cracking and Stress Corrosion Cracking in H2S Environments. Houston, Texas. 2016. 